\title{
OPACIDADES EM VIDRO FOSCO NAS DOENÇAS PULMONARES DIFUSAS: CORRELAÇ̃̃O DA TOMOGRAFIA COMPUTADORIZADA DE ALTA RESOLUÇÃO COM A ANATOMOPATOLOGIA*
}

\author{
Maria Lúcia de Oliveira Santos ${ }^{1}$, Edson Marchiori ${ }^{2}$, Alberto Domingues Vianna ${ }^{1}$, Arthur Soares \\ Souza Jr. ${ }^{3}$, Heleno Pinto de Moraes ${ }^{4}$
}

Resumo Opacidade em vidro fosco é achado freqüentemente visto na tomografia computadorizada de alta resolução do tórax e se traduz pelo aumento do coeficiente de atenuação dos pulmões, mas sem apagar as marcas broncovasculares. Por sua inespecificidade, a associação com outros achados radiológicos, clínicos e anatomopatológicos deve ser considerada para uma interpretação diagnóstica mais correta. Neste trabalho foram analisados 62 exames tomográficos de pacientes com doenças pulmonares difusas, de 14 etiologias diferentes, em que opacidades em vidro fosco foram o achado único ou predominante, e feita correlação anatomopatológica por meio de biópsias ou necropsias. Na pneumocistose as opacidades em vidro fosco corresponderam, histologicamente, à ocupação alveolar por material espumoso contendo parasitos; no carcinoma bronquíolo-alveolar, a espessamento dos septos alveolares e ocupação de sua luz por muco e células tumorais; na paracoccidioidomicose, a espessamento dos septos alveolares, áreas de fibrose e alvéolos contendo exsudato broncopneumônico; na sarcoidose, a fibrose ou a acúmulo de granulomas; na fibrose pulmonar idiopática, a espessamento dos septos alveolares por fibrose; na bronquiolite obliterante com pneumonia em organização, a pneumonia intersticial com áreas de organização intra-alveolar. A ocupação alveolar por sangue foi observada nos casos de leptospirose, hemossiderose idiopática, metástases de tumor renal e na aspergilose invasiva; por vacúolos de gordura na pneumonia lipídica; por material protéico e lipoprotéico na silicoproteinose e na proteinose alveolar; e por líquido de edema na insuficiência cardíaca congestiva. Unitermos: Opacidade em vidro fosco; Pulmões; Tomografia computadorizada de alta resolução.

Abstract Ground-glass opacity in diffuse lung diseases: high-resolution computed tomography-pathology correlation. Ground-glass opacity is a finding frequently seen in high-resolution computed tomography examinations of the chest and is characterized by hazy increased attenuation of lung, however without blurring of bronchial and vascular margins. Due to its unspecificity, association with other radiological, clinical and pathological findings must be considered for an accurate diagnostic interpretation. In this paper were reviewed $62 \mathrm{com}$ puted tomography examinations of patients with diffuse pulmonary diseases of 14 different etiologies in which ground-glass opacity was the only or the most remarkable finding, and correlated this findings with pathology abnormalities seen on specimens obtained from biopsies or necropsies. In pneumocystosis, groundglass opacities correlated histologically with alveolar occupation by a foaming material containing parasites, in bronchioloalveolar cell carcinoma with thickening of the alveolar septa and occupation of the lumen by mucus and tumoral cells, in paracoccidioidomycosis with thickening of the alveolar septa, areas of fibrosis and alveolar bronchopneumonic exsudate, in sarcoidosis with fibrosis or clustering of granulomas and in idiopathic pulmonary fibrosis with alveolar septa thickening due to fibrosis. Alveolar occupation by blood was found in cases of leptospirosis, idiopathic hemosiderosis, metastatic kidney tumor and invasive aspergillosis whereas oily vacuoli were seen in lipoid pneumonia, proteinaceus and lipoproteinaceus material in silicoproteinosis and pulmonary alveolar proteinosis, and edematous fluid in cardiac failure.

Key words: Ground-glass opacity; Lungs; High-resolution computed tomography.

* Trabalho realizado no Departamento de Radiologia da Universidade Federal Fluminense (UFF), Niterói, RJ, e no Serviço de Radiodiagnóstico do Hospital Universitário Clementino Fraga Filho (HUCFF) da Universidade Federal do Rio de Janeiro (UFRJ), Rio de Janeiro, RJ.

1. Professores Adjuntos de Radiologia da UFF.

2. Professor Titular de Radiologia da UFF, Coordenador Adjunto do Curso de Pós-Graduação em Radiologia da UFRJ.

3. Professor Adjunto de Radiologia da Faculdade de Medicina de São José do Rio Preto (Famerp), SP.

4. Professor Adjunto de Patologia da UFF.

Endereço para correspondência: Prof. Dr. Edson Marchiori. Rua Thomaz Cameron, 438, Valparaíso. Petrópolis, RJ, 25685-120. E-mail: edmarchiori@zipmail.com.br

Recebido para publicação em 20/3/2003. Aceito, após revisão, em 12/5/2003.

\section{INTRODUÇÃO}

Opacidade em vidro fosco, ou atenuação em vidro fosco, é um aspecto descrito na tomografia computadorizada de alta resolução (TCAR) dos pulmões, no qual ocorre aumento do coeficiente de atenuação do parênquima, com preservação das marcas broncovasculares ${ }^{(\mathbf{1}, \mathbf{2})}$.

Pode ser determinado por preenchimento ou colapso parcial dos alvéolos, por espessamento intersticial, por aumento do volume sanguíneo capilar, ou por expiração normal. Pode vir acompanhado de broncograma aéreo, o que muitas vezes leva a confundir com áreas de consolidação; porém, o que o diferencia destas é a identificação das marcas vasculares na opacidade em vidro fosco ${ }^{(\mathbf{1})}$.

Apesar de ser um aspecto freqüentemente observado, é, na maior parte das vezes, inespecífico, mas, quando associado 
com os dados clínicos e com outros achados tomográficos, pode sugerir um diagnóstico específico, bem como ser útil no acompanhamento evolutivo de doenças, além de servir de referência para o cirurgião ou para o broncoscopista na escolha do local para a realização de biópsias ou de lavado broncoalveolar ${ }^{(\mathbf{1})}$.

Atualmente, considera-se que este padrão possa ser encontrado nas fases agudas ou crônicas de doenças que comprometem o interstício e/ou os alvéolos das mais variadas naturezas. A extensão, distribuição, forma de apresentação e associação com outros achados tomográficos são condições que, quando associadas à clínica, podem caracterizar doenças específicas em determinadas fases do seu curso.

No presente estudo foram analisadas as TCAR de 62 pacientes com doenças pulmonares difusas de 14 etiologias diferentes, nas quais o padrão em vidro fosco foi o achado principal, sendo estabelecida a correlação anatomopatológica por meio de biópsias a céu aberto ou de necropsias.

Os objetivos deste trabalho são discutir as principais doenças que apresentam opacidades em vidro fosco como achado único ou predominante, o significado deste achado e a sua associação com outros padrões tomográficos, e correlacionar estes aspectos com o seu substrato anatomopatológico.

\section{MATERIAIS E MÉTODOS}

Neste trabalho foram estudadas, retrospectivamente, as TCAR de tórax de 64 pacientes que apresentavam opacidade em vidro fosco. Eles foram selecionados de um grupo de 213 pacientes submetidos a TCAR para avaliação de doenças pulmonares difusas, nas quais opacidade em vidro fosco eventualmente é um achado expressivo ou predominante, e que obtiveram comprovação diagnóstica por meio de exames anatomopatológicos, por correlação clínico-radiológica ou por resposta terapêutica adequada.

Estes casos foram reunidos aleatoriamente dos arquivos de ensino de diversas instituições dos estados do Rio de Janeiro e de São Paulo.

Foram selecionados os pacientes que apresentavam opacidade em vidro fosco como achado único ou como achado significativo, mesmo quando associado a outras alterações. Não foram considerados aqueles exames que apresentavam discutíveis áreas com este padrão, de permeio a outras lesões de maior importância, ou os casos em que os critérios de comprovação diagnóstica eram passíveis de questionamento.

Dos 213 casos, foram selecionados 64 pacientes com doenças pulmonares difusas e que apresentavam opacidade em vidro fosco na TCAR $(30,4 \%)$, correspondendo a 16 diferentes doenças. Dois desses 64 pacientes - um com pneumonia intersticial descamativa e o outro com alveolite alérgica extrínseca - foram excluídos porque não se obteve o material anatomopatológico para correlação. Dessa forma, o estudo final foi realizado com as TCAR de 62 pacientes, correspondendo a 14 diferentes doenças, das quais se obteve material anatomopatológico em quantidade e qualidade adequadas para a correlação anátomo-radiológica de pelo menos um dos casos de cada.

Foram encontrados 14 casos de pneumocistose, 11 de sarcoidose, nove de paracoccidioidomicose, sete de carcinoma bronquíolo-alveolar, cinco de fibrose pulmonar idiopática e três de bronquiolite obliterante com pneumonia em organização. Foram também observados dois casos de insuficiência cardíaca congestiva, de leptospirose, de proteinose alveolar, de silicose aguda e de pneumonia lipídica; e um caso de aspergilose invasiva, de hemossiderose idiopática e de metástases hematogênicas (Tabela 1).

Quanto à rotina de exame, o estudo retrospectivo, feito com exames provenientes de diferentes instituições, não permitiu uma padronização adequada dos protocolos utilizados.

De maneira geral, todos os exames foram feitos com a técnica de alta resolução, que consiste em cortes finos, variando de 1 a $2 \mathrm{~mm}$ de espessura, com intervalos de $10 \mathrm{~mm}$, dos ápices pulmonares até a cúpula diafragmática, com reconstruções utilizando-se o algoritmo de alta resolução espacial, com o paciente em posição supina. $\mathrm{O}$ registro dos casos foi feito em filme radiológico, com janelas variando de 1.200 a 1.600 UH e níveis entre -450 e -650 UH, dependendo do aparelho utilizado em cada instituição. Para o estudo do parênquima pulmonar, em nenhum dos casos foi empregado meio de contraste iodado. Não foi objetivo deste estudo a avaliação de alterações extraparenquimatosas (hilares, mediastinais ou pleurais).

Tabela 1 Doenças pulmonares difusas estudadas, com padrão de vidro fosco significativo na TCAR.

\begin{tabular}{|c|c|c|c|c|c|c|}
\hline Doença & $\begin{array}{l}\text { № de } \\
\text { casos }\end{array}$ & PVF+ & $\begin{array}{l}\text { Porcenta- } \\
\text { gem }\end{array}$ & Mas. & Fem. & $\begin{array}{l}\text { Idade } \\
\text { média } \\
\text { (anos) }\end{array}$ \\
\hline Pneumocistose & 14 & 14 & $100 \%$ & 10 & 4 & 38 \\
\hline Sarcoidose & 22 & 11 & $50 \%$ & 11 & 11 & 47 \\
\hline Paracoccidioidomicose & 15 & 9 & $60 \%$ & 14 & 1 & 60 \\
\hline Carcinoma bronquíolo-alveolar & 9 & 7 & $77,7 \%$ & 9 & - & 55 \\
\hline Fibrose pulmonar idiopática & 11 & 5 & $45,4 \%$ & 6 & 5 & 57 \\
\hline $\begin{array}{l}\text { Bronquiolite obliterante com pneumonia } \\
\text { em organização }\end{array}$ & 3 & 3 & $100 \%$ & 1 & 2 & 32 \\
\hline Insuficiência cardíaca congestiva & 2 & 2 & $100 \%$ & 1 & 1 & 55 \\
\hline Leptospirose & 2 & 2 & $100 \%$ & 2 & - & 24 \\
\hline Proteinose alveolar & 2 & 2 & $100 \%$ & 2 & - & 40 \\
\hline Silicose aguda & 2 & 2 & $100 \%$ & 2 & - & 25 \\
\hline Pneumonia lipídica & 2 & 2 & $100 \%$ & 2 & - & 43 \\
\hline Aspergilose invasiva & 1 & 1 & $100 \%$ & 1 & - & 47 \\
\hline Hemossiderose idiopática & 1 & 1 & $100 \%$ & 1 & - & 39 \\
\hline Metástases hematogênicas & 11 & 1 & $9,1 \%$ & 6 & 5 & 53 \\
\hline $\begin{array}{l}\text { Excluídos por falta de material anatomo- } \\
\text { patológico }\end{array}$ & 2 & 2 & - & - & - & - \\
\hline Total & 99 & 64 & - & - & - & - \\
\hline
\end{tabular}

PVF, padrão em vidro fosco; Mas., masculino; Fem., feminino. 


\section{RESULTADOS E DISCUSSÃO}

\section{Pneumocistose}

Todos os 14 pacientes estudados com pneumocistose apresentavam opacidade em vidro fosco. A alta incidência deste padrão nas TCAR de pacientes com pneumonia por Pneumocystis carinii também foi relatada por vários autores ${ }^{(\mathbf{3 , 4})}$.

Onze pacientes apresentaram opacidade em vidro fosco com distribuição difusa, heterogênea, e três o padrão de pavimentação em mosaico (Figura 1A). O achado de opacidade em vidro fosco com distribuição difusa está de acordo com vários autores $^{(3,5)}$. Com relação à pavimentação em mosaico, no nosso estudo houve concordância com Primack e Müller ${ }^{(5)}$ e Pereira et al. ${ }^{(\mathbf{4})}$, que também encontraram pequeno porcentual deste aspecto, diferindo, entretanto, de McGuinness ${ }^{(6)}$, que relatou alta incidência de pavimentação em mosaico na pneumonia por $P$. carinii.

Em seis dos nossos pacientes o diagnóstico foi estabelecido em função dos achados clínicos, associados à resposta à terapêutica específica. Viegas et al. ${ }^{(7)}$ concluíram que, nos pacientes com quadro típico de pneumonia por $P$. carinii, o diagnóstico clínico constitui uma alternativa eficaz, quando há dificuldade de realização do exame histopatológico.

No nosso estudo, os achados histológicos foram a presença de material espumoso contendo parasitos no interior de alvéo- los, e alguns septos espessados por edema e elementos celulares (Figura 1B), de acordo com o descrito na literatura ${ }^{(3,6)}$.

\section{Sarcoidose}

Neste estudo foram observadas opacidades em vidro fosco em $11(50 \%)$ dos 22 pacientes com sarcoidose. Brauner et al. ${ }^{(\mathbf{8})}$ observaram este padrão em $75 \%$ dos seus casos. Em dez de nossos casos houve a apresentação esparsa pelo parênquima, e em apenas um deles a forma difusa. No caso com distribuição difusa e em cinco dos casos com distribuição esparsa estavam presentes micronódulos, cissuras nodulares, nódulos subpleurais e espessamento nodular do interstício axial (Figura 2A). Achados semelhantes a estes também foram relatados na literatura ${ }^{(8-10)}$.

Nos pacientes em que foi possível a realização do estudo anatomopatológico, foram observados granulomas com distribuição perilinfática, sendo que, nas áreas correspondentes às opacidades em vidro fosco, havia também granulomas no interstício intralobular (Figura 2B), o que está de acordo com a literatura $^{(\mathbf{8 - 1 0 )}}$.

\section{Paracoccidioidomicose}

Opacidades em vidro fosco foram encontradas em nove $(60 \%)$ dos 15 pacientes estudados com paracoccidioidomicose, um porcentual maior do que o encontrado por Funari et al. ${ }^{(11)}$ (34\%) e Kauer ${ }^{(12)}$ $(32,1 \%)$, porém bem próximo dos relata- dos por Marchiori et al. ${ }^{(\mathbf{1 3})}(61,5 \%)$ e Muniz et al. ${ }^{(14)}(66,7 \%)$.

As opacidades em vidro fosco distribuíram-se aleatoriamente em seis casos, em um predominando nos dois terços superiores e em dois, nos dois terços inferiores, sendo que em um predominaram nas regiões posteriores. Espessamento de septos interlobulares associado a opacidades em vidro fosco foi observado em sete casos (46\%), em geral pouco expressivos, em discordância com os altos porcentuais descritos na literatura $^{(\mathbf{1 2 - 1 4})}$. Áreas de atenuação em vidro fosco relacionadas a enfisema e distorção parenquimatosa foram observadas em apenas dois casos (Figura 3A).

Os estudos anatomopatológicos mostraram infiltrado inflamatório nos septos alveolares, além de áreas de fibrose (Figura 3B). Foi também observado que material com presença de exsudato intra-alveolar tipo broncopneumônico correspondia à área de consolidação visualizada na TCAR. Estes achados são semelhantes aos relatados na literatura $^{(\mathbf{1 5})}$.

\section{Carcinoma bronquíolo-alveolar}

Neste trabalho, as opacidades em vidro fosco observadas em sete pacientes com carcinoma bronquíolo-alveolar ocorreram nas formas difusas da doença. Estes achados são semelhantes aos encontrados por Moreira et al. ${ }^{(\mathbf{1 6})}$ e Akira et al. ${ }^{(\mathbf{1 7 )}}$, mas diferem dos descritos por Jang et al. ${ }^{(\mathbf{1 8})}$, que observaram opacidades em vidro fosco

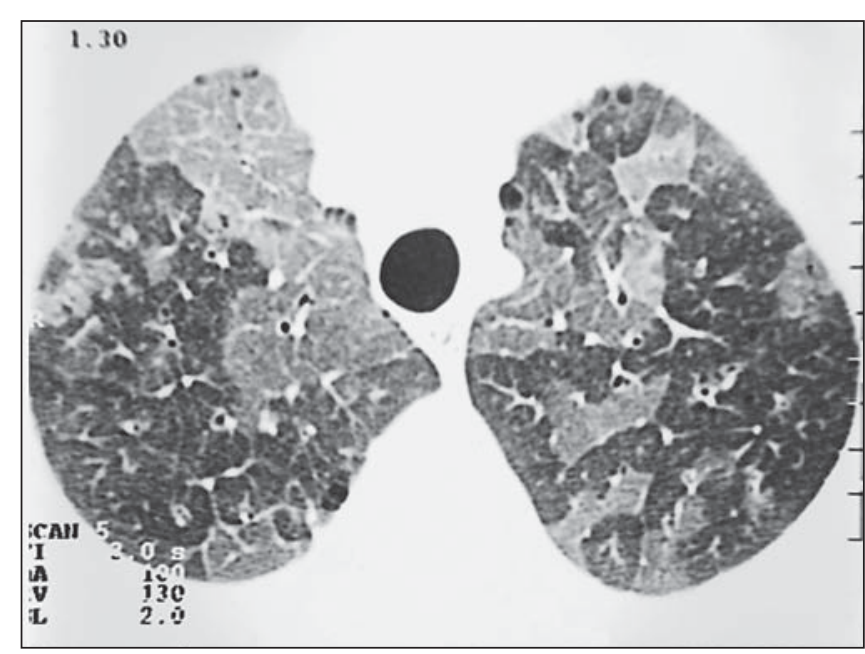

A

Figura 1. Pneumocistose. Em A, TCAR com aspecto de pavimentação em mosaico, lóbulos secundários comprometidos, ladeados por lóbulos normais e septos interlobulares espessados de permeio, predominando no segmento anterior do lobo superior direito. Em B, corte histológico mostrando septo interlobular espessado por edema e elementos celulares, separando dois lóbulos secundários comprometidos.

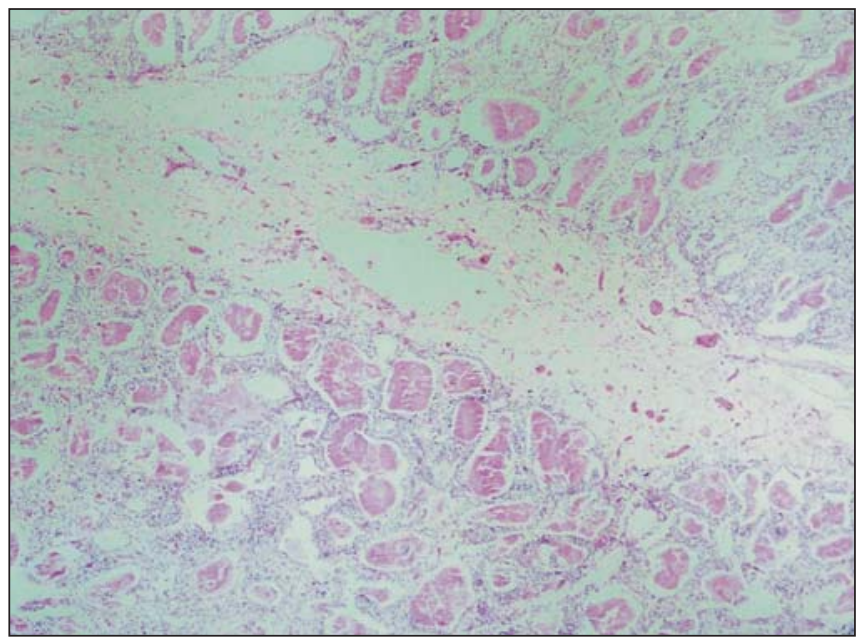

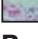




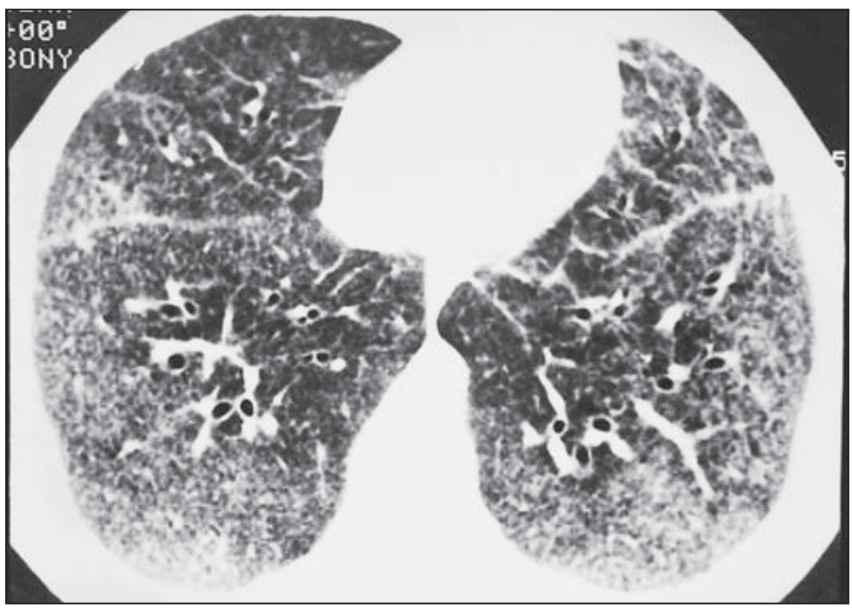

A

Figura 2. Sarcoidose. Em A, TCAR mostrando opacidade em vidro fosco predominando na periferia dos pulmões, com aspecto granular, discreto espessamento de septos interlobulares e nódulos cissurais. Em B, corte histológico com múltiplos granulomas esparsos pelo interstício parenquimatoso.

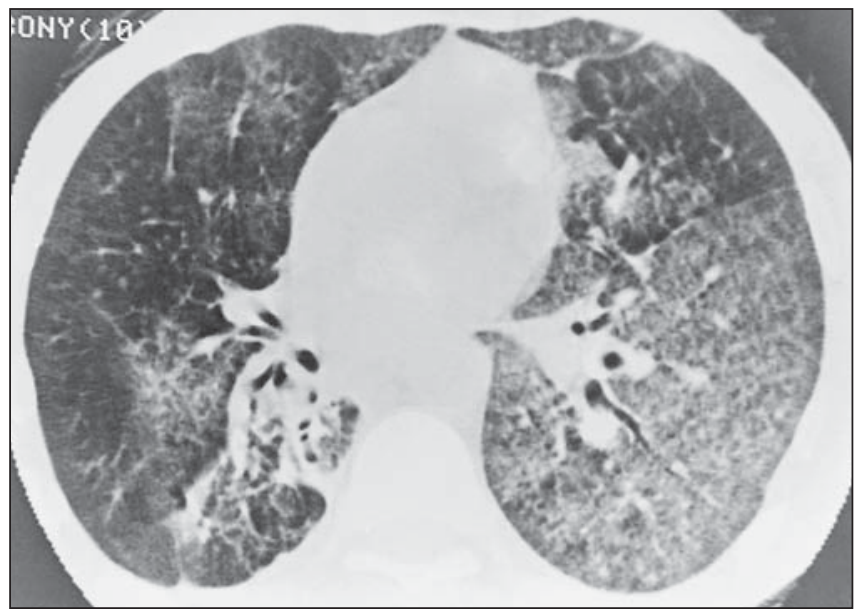

A

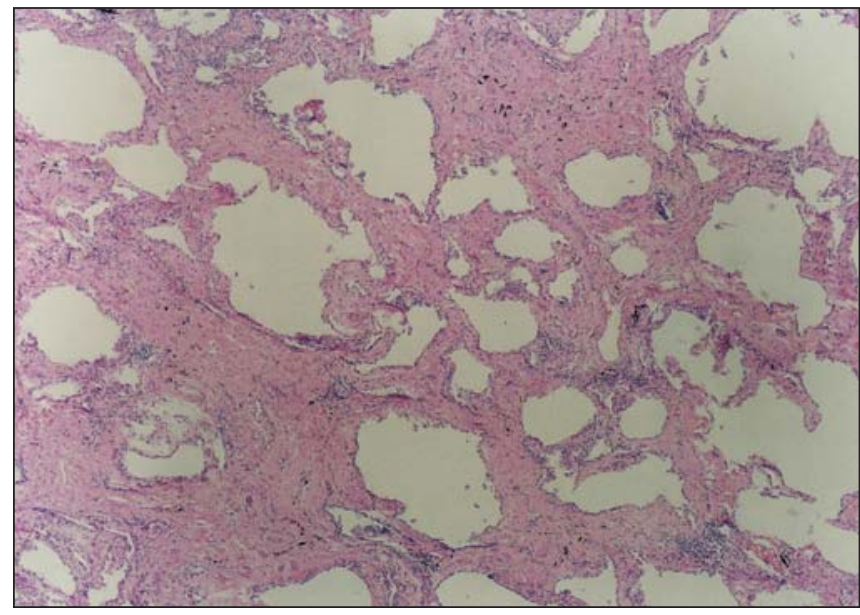

B

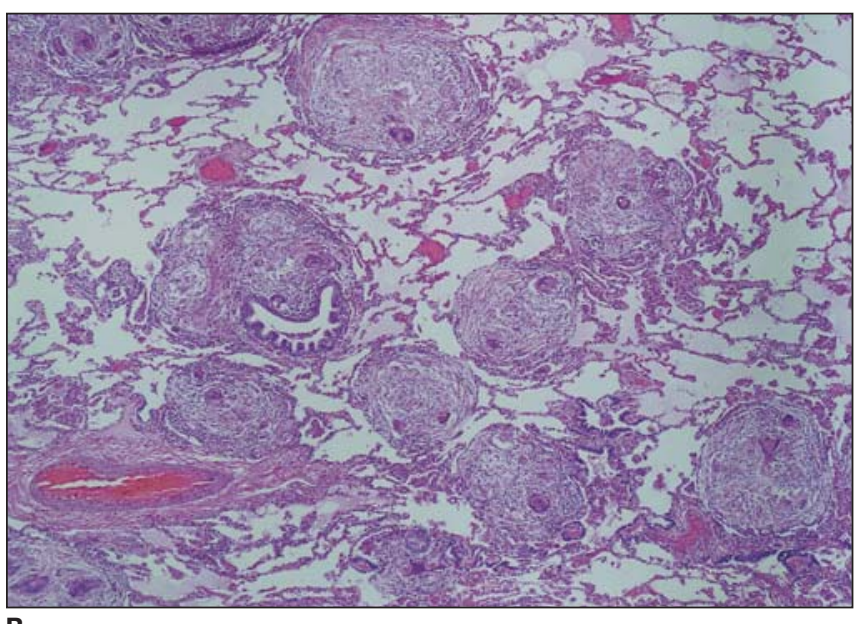

B

Figura 3. Paracoccidioidomicose. Em A, TCAR evidenciando áreas de atenuação em vidro fosco intercaladas com zonas enfisematosas, além de bandas parenquimatosas, septos interlobulares espessados e evidências de distorção da arquitetura parenquimatosa. Em $\mathbf{B}$, corte histológico demonstrando que as áreas de vidro fosco correspondiam a fibrose nos septos alveolares. Observar, também, aspecto de enfisema associado.

como aspecto mais freqüente, porém na forma focal do carcinoma bronquíolo-alveolar. Ainda segundo Jang et al. ${ }^{(\mathbf{1 8})}$, dos quatro pacientes com áreas focais em vidro fosco, dois apresentavam consolidação associada, o que, no presente trabalho, foi encontrado em três casos, levando à suspeição da presença da forma mucinosa do carcinoma bronquíolo-alveolar.

A pavimentação em mosaico, descrita por Tan e $\mathrm{Kuzo}^{(\mathbf{1 9})}$, foi encontrada em quatro dos nossos casos (Figura 4A). Segundo Marchiori et al. ${ }^{(\mathbf{2 0 , 2 1 )}}$, a pavimentação em mosaico é dada pela ocupação parcial do lúmen alveolar por células tumorais ou muco, associada a espessamento dos septos interlobulares, por linfangite. Este as- pecto também foi observado por Kobayashi et al. $^{(\mathbf{2 2})}$, ao descreverem opacidades em vidro fosco na sua apresentação difusa.

Os estudos histológicos demonstraram a presença de células tumorais revestindo os septos alveolares, e de muco no interior dos alvéolos, além de linfangite nos septos interlobulares (Figuras 4B e 4C), o que está consoante com a literatura ${ }^{(\mathbf{1 9 - 2 2})}$.

\section{Fibrose pulmonar idiopática}

Cinco dos 11 pacientes com fibrose pulmonar idiopática apresentaram opacidades em vidro fosco na TCAR. $\mathrm{O}$ aspecto tomográfico encontrado foi o de opacidades em vidro fosco ocupando preferencialmente as porções posteriores e sub- pleurais dos pulmões, vistas de permeio a áreas císticas de paredes relativamente espessas, compartilhadas, formando camadas empilhadas nas regiões subpleurais, compatíveis com faveolamento (Figura 5A), além de outras evidências de fibrose (distorção arquitetural, bronquiolectasias e áreas de faveolamento). Reticulado intralobular e espessamento septal foram observados junto às áreas de opacidade em vidro fosco em três casos.

O estudo histológico mostrou extenso comprometimento intersticial com espessamento de septos interlobulares e alveolares, por infiltração de fibroblastos, além de bronquiolectasias e faveolamento ( $\mathrm{Fi}$ gura 5B), como descrito na literatura ${ }^{(23)}$. 
Figura 4. Carcinoma bronquíolo-alveolar. Em A, TCAR demonstrando padrão de pavimentação em mosaico, melhor visto nas regiões anteriores do pulmão direito, além de extensas áreas de consolidação, com broncograma aéreo, em ambos os pulmões. Notar áreas hipodensas de permeio às consolidações, que correspondem a acúmulo de muco. Em B, corte histológico mostrando septos interlobulares espessados, separando lóbulo extensamente comprometido, à esquerda, de outro relativamente preservado. Observar células neoplásicas no interior de linfáticos do septo interlobular (linfangite carcinomatosa). Em C, acúmulo de muco produzido pelo tumor, ocupando parcialmente os espaços alveolares.
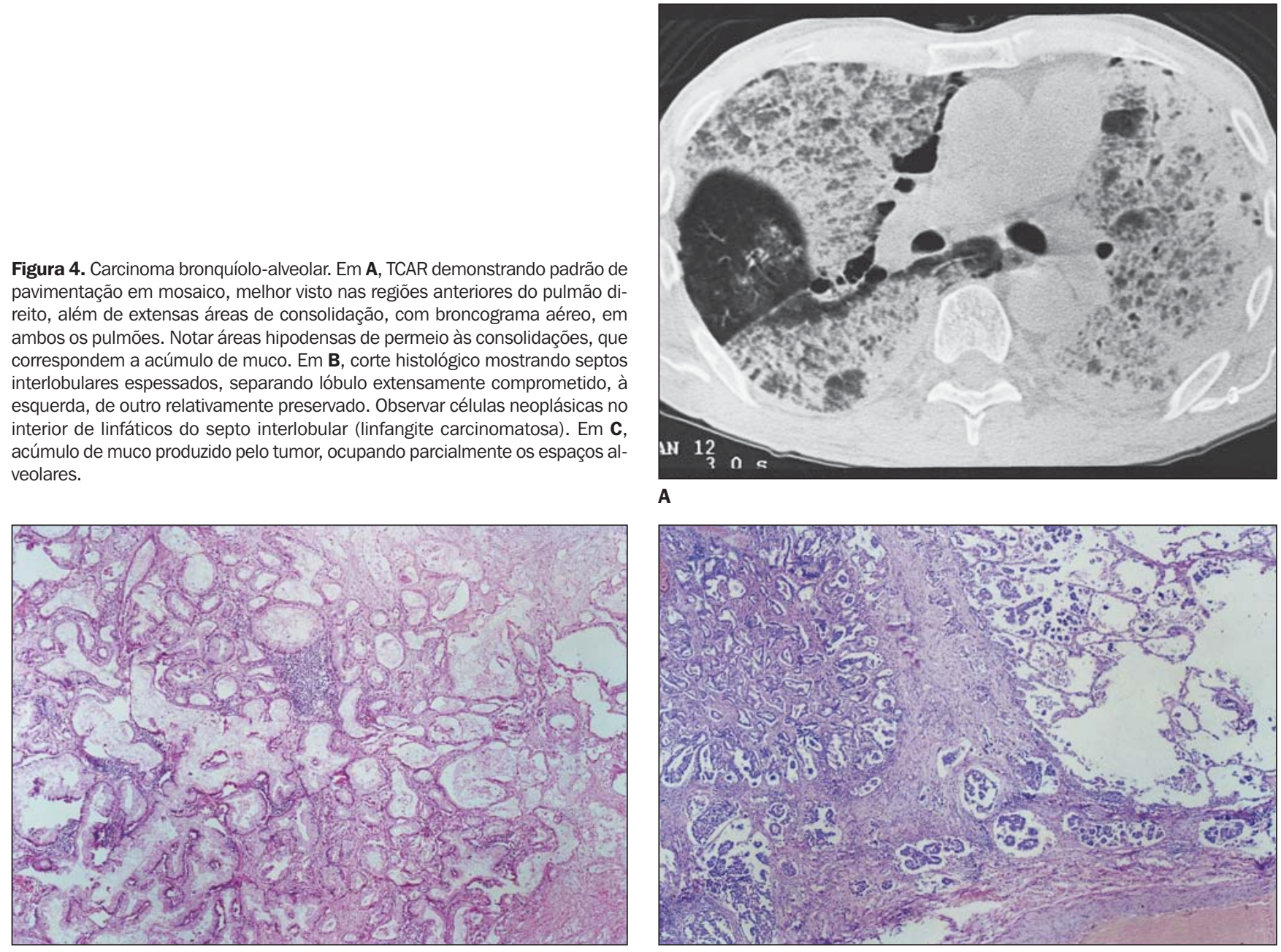

A

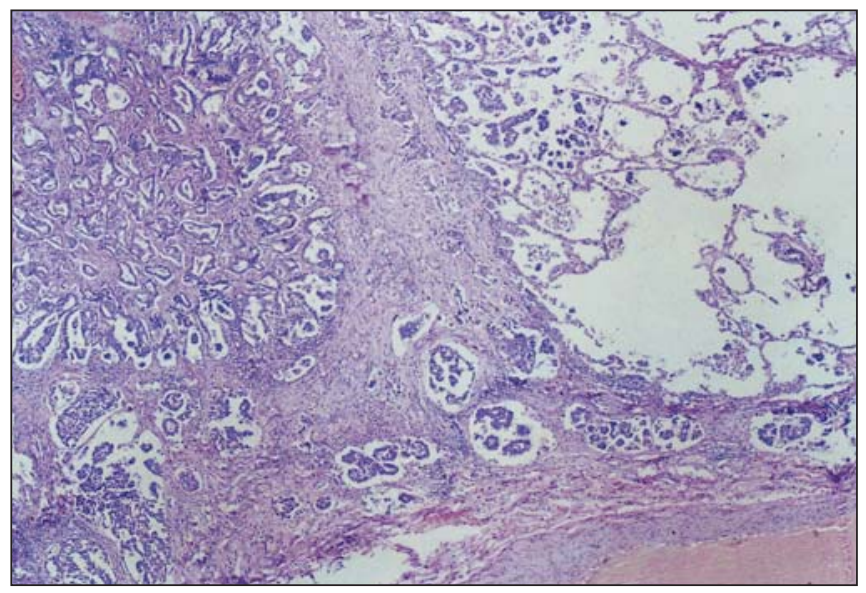

C
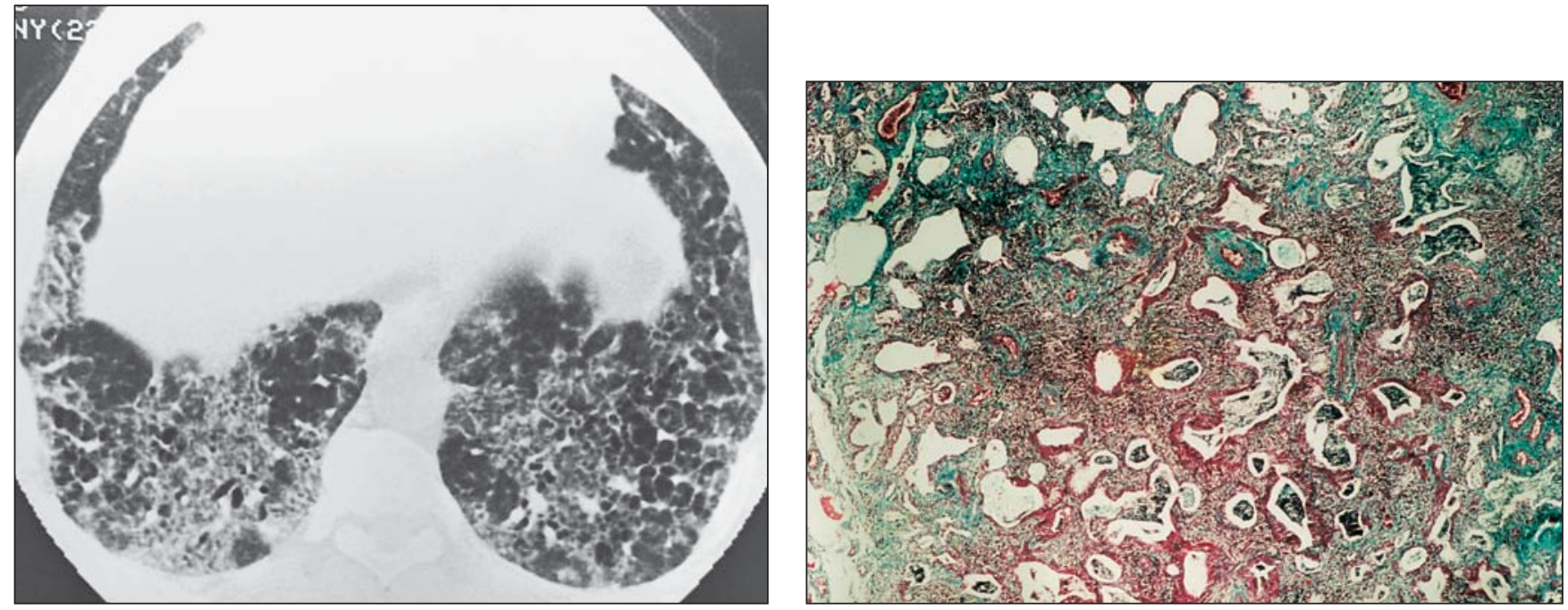

A

Figura 5. Fibrose pulmonar idiopática. Em A, TCAR de campos inferiores, onde se observam áreas de opacidades em vidro fosco, especialmente na base direita, com broquiolectasias e cistos de faveolamento de permeio. Em B, corte histológico da região demonstrando que as áreas em vidro fosco correspondiam essencialmente ao espessamento dos septos alveolares, por fibrose. Observa-se, também, aspecto de bronquiolectasias e faveolamento microscópico. 


\section{Bronquiolite obliterante com pneumonia em organização}

Três casos de bronquiolite obliterante com pneumonia em organização foram observados. As opacidades em vidro fosco acometiam principalmente os lobos inferiores, com distribuição subpleural, esparsa, salteada; elas estiveram associadas a áreas de consolidação e ao espessamento de septos interlobulares (Figura 6A). Dilatação brônquica e áreas de vidro fosco de aspecto triangular subpleural foram observadas em todos os casos.

Akira et al. ${ }^{(24)}$ descreveram três padrões radiográficos para a bronquiolite obliterante com pneumonia em organização: o infiltrado reticular, difuso, periférico, de localização subpleural, a forma pneumônica e a forma nodular localizada. As paredes brônquicas espessadas, com luz dilatada, na presença de consolidações, além da presença de infiltrados alveolares com formato triangular e base na superfície pleural, também foram descritos por outros autores $^{(25,26)}$.

Histologicamente, a inflamação dos septos alveolares, a descamação celular intra-alveolar e a presença de tecido de granulação no espaço aéreo terminal caracterizam a bronquiolite obliterante com pneumonia em organização e são responsáveis pelo padrão em vidro fosco na TCAR ${ }^{(27,28)}$.

Os estudos histopatológicos obtidos demonstraram a presença de pneumonia intersticial com áreas de organização intra- alveolar e bronquiolite obliterante secundária à presença de pólipos no interior dos brônquios, obstruindo-os parcialmente (Figura 6B), o que está consoante com a literatura $^{(27,28)}$.

\section{Insuficiência cardíaca congestiva}

Nos dois pacientes com insuficiência cardíaca congestiva foram observadas opacidades em vidro fosco de comprometimento difuso, com predominância nos lobos inferiores. Aumento das dimensões cardíacas, espessamento dos septos interlobulares e derrame pleural foram achados associados (Figura 7A).

Segundo Storto et al. ${ }^{(\mathbf{2 9})}$, das alterações encontradas na TCAR de sete pacientes com edema pulmonar, as opacidades em vidro fosco foram as mais freqüentes, seguidas do espessamento dos septos interlobulares e espessamento intersticial peribroncovascular.

Os achados anatomopatológicos mostraram alvéolos parcialmente ocupados e septos interlobulares espessados uniformemente, ambos por edema (Figura 7B). Segundo Storto et al. ${ }^{(\mathbf{2 9 )}}$, o espessamento de septos interlobulares secundário ao edema pulmonar ocorre por acúmulo de líquido no interstício, com ou por disseminação uniforme e delicada. Quando é observado um aspecto nodular focal, geralmente está ocorrendo um aumento do calibre venoso intra-septal. Este aspecto não foi observado no presente trabalho.

\section{Leptospirose}

Os dois pacientes com leptospirose apresentaram opacidades em vidro fosco heterogêneas. Sua distribuição foi predominantemente periférica, subpleural e nas regiões póstero-inferiores dos pulmões (Figura 8A). A associação com áreas de consolidação pôde ser vista em um caso. O espessamento dos septos interlobulares não foi observado.

Estes achados são concordantes com os encontrados por Marchiori e Müller ${ }^{(30)}$. Segundo esses autores, na análise dos seus cinco casos também foram encontrados nódulos centrolobulares, nódulos do espaço aéreo e derrame pleural, não observados no presente trabalho.

Anatomopatologicamente, são descritas superfícies de corte hemorrágicas, com lesões que sugerem infartos hemorrágicos, além de petéquias na superfície pleural. Microscopicamente, são observados congestão pulmonar, focos de hemorragia alveolar e intersticial e edema pulmonar ${ }^{(31)}$. O estudo anatomopatológico em um dos casos deste estudo demonstrou ocupação alveolar maciça e intersticial esparsa, por sangue (Figura 8B), concordando com a literatura $^{(31)}$.

\section{Proteinose alveolar}

Analisadas as TCAR dos dois pacientes com proteinose alveolar, foi observada a presença de opacidades em vidro fosco em ambas, associadas ao espessamento de

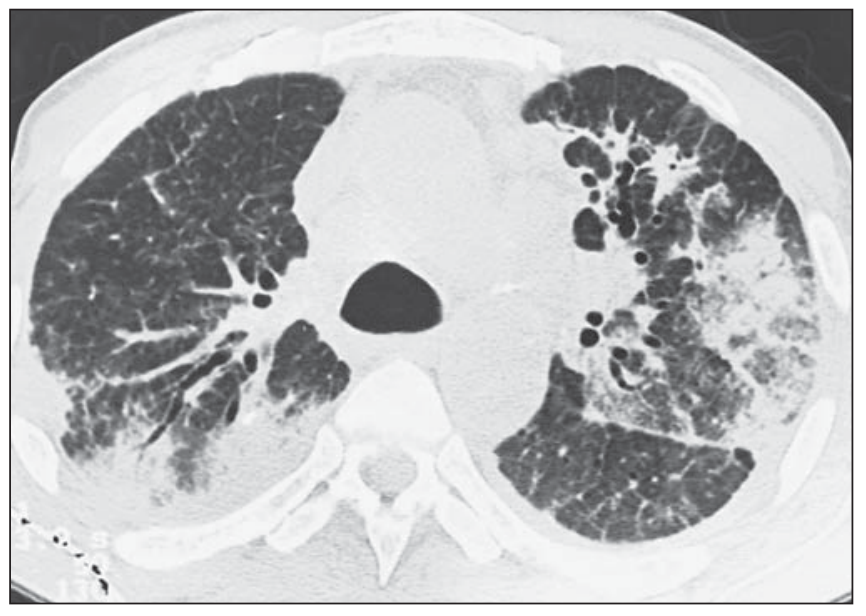

A

Figura 6. Bronquiolite obliterante com pneumonia em organização. Em A, TCAR mostrando áreas de consolidação periféricas em ambos os pulmões, com broncograma aéreo de permeio, e áreas de atenuação em vidro fosco à esquerda. Observar, também, espessamento de septos interlobulares. Em B, corte histológico mostrando alvéolos normais à direita da foto, pneumonia em organização à esquerda e brônquio com paredes espessas e pólipo intraluminal na região central. 


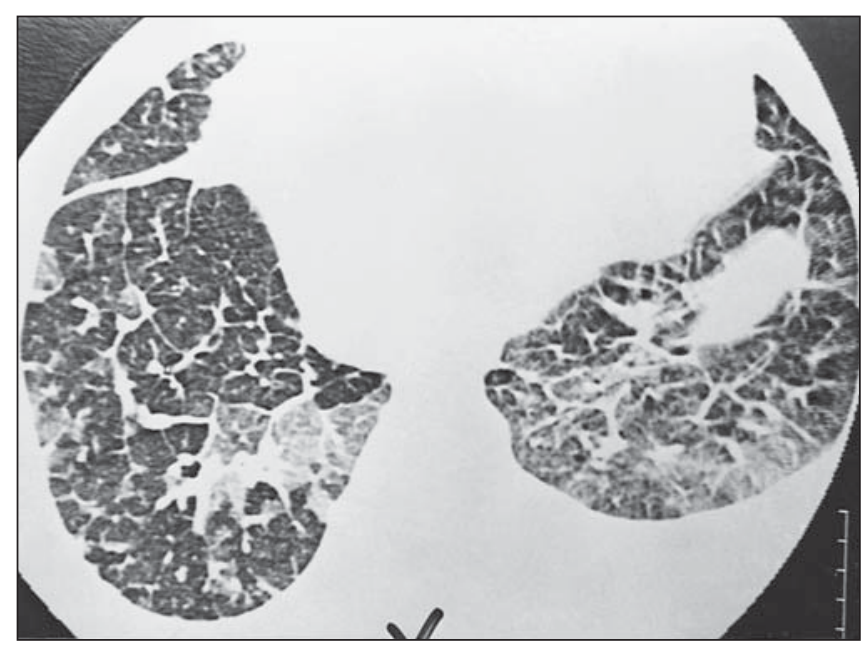

A

B

Figura 7. Insuficiência cardíaca congestiva. Corte mostrando áreas de opacidade em vidro fosco associadas a espessamento de septos interlobulares, além de aumento das dimensões cardíacas e evidência de derrame pleural esquerdo. Em B, corte histológico da periferia pulmonar, em que se observam espaços alveolares e septo interlobular preenchidos por edema.

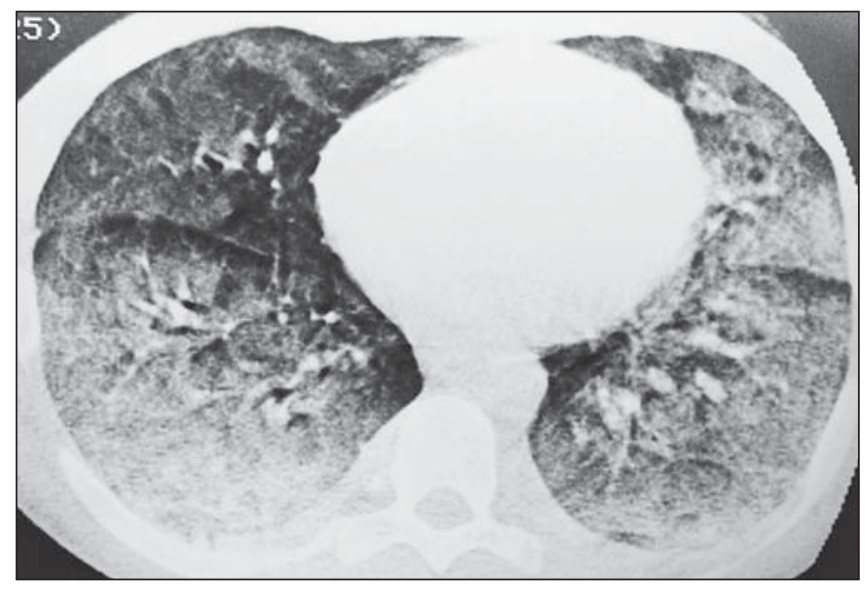

A

Figura 8. Leptospirose. Em A, TCAR mostrando opacidades em vidro fosco de distribuição bilateral, ocupando mais acentuadamente a cortical dos pulmões, com predomínio nas porções posteriores. Em B, corte histológico mostrando espaços alveolares contendo sangue.

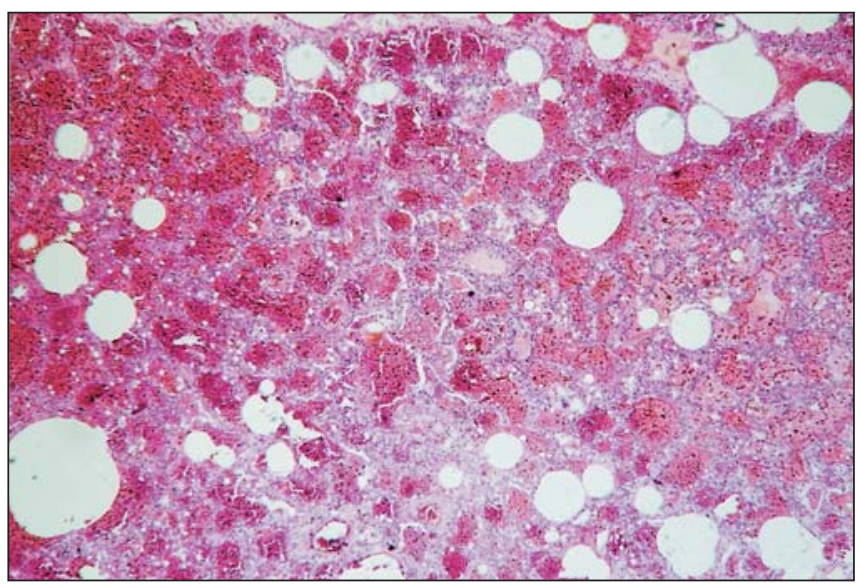

B

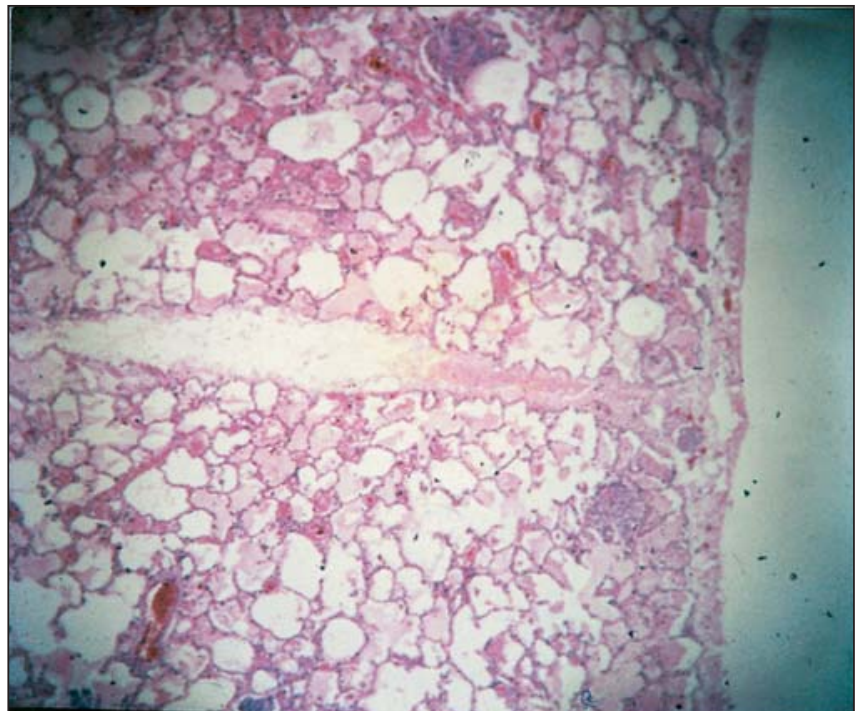

\section{(1)}



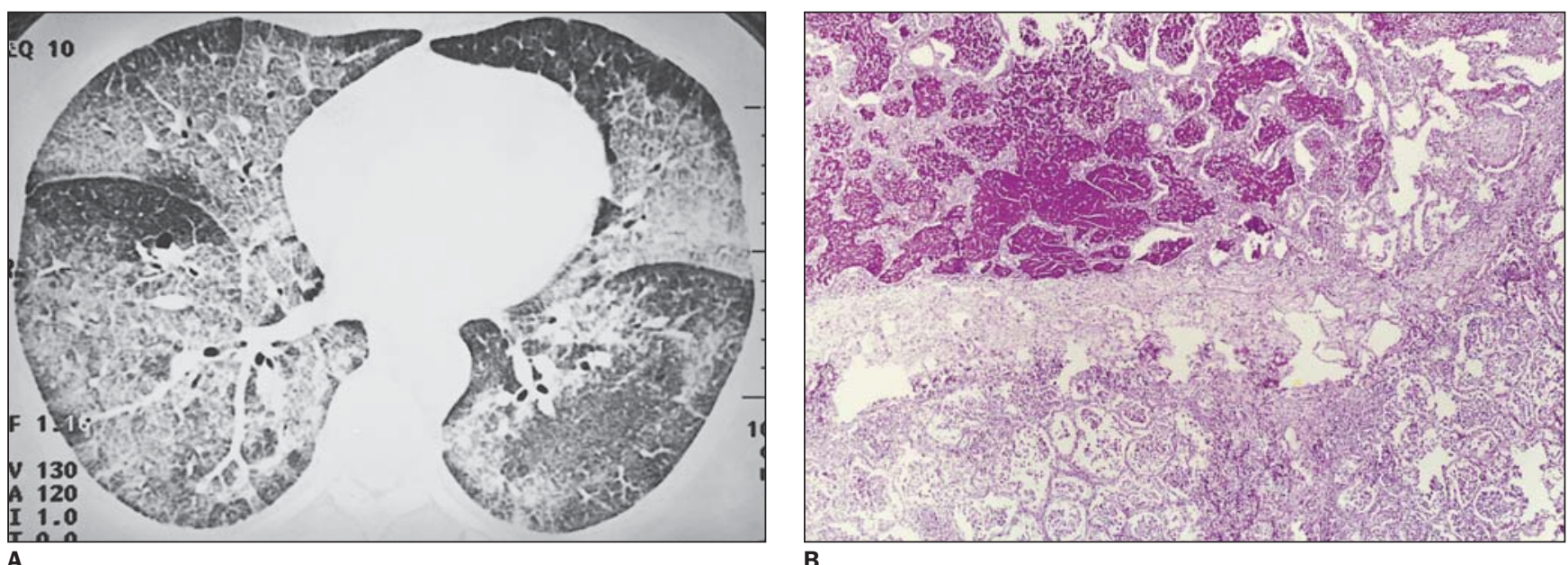

Figura 9. Proteinose alveolar. Em A, TCAR apresentando opacidades em vidro fosco e septos interlobulares espessados de permeio, esparsos pelos pulmões. Aspecto de pavimentação em mosaico. Em B, corte histológico (corado pelo ácido periódico de Schiff) mostrando ocupação alveolar por material lipoprotéico PAS positivo. Observa-se, também, septo interlobular separando lóbulo comprometido (superiormente) de outro lóbulo relativamente preservado (inferiormente).

\section{Pneumonia lipídica}

Foram estudados dois pacientes com pneumonia lipídica. Em um deles (paciente de dois anos de idade, que aspirou óleo mineral), as opacidades em vidro fosco foram observadas de forma difusa, bilateral e simétrica, com áreas de confluência ocupando tanto a cortical como a medular dos pulmões, contendo septos interlobulares espessados de permeio (pavimentação em mosaico). No outro caso (paciente de 83 anos de idade, com história de aspiração crônica de óleo de rícino), o padrão em vidro fosco foi observado acompanhando áreas de consolidação isoladas, distribuídas esparsamente pelas regiões posteriores dos pulmões, com predominância à direita. Septos espessados foram observados junto às opacidades em vidro fosco.

Segundo Wheeler et al. ${ }^{(36)}$, a TCAR é o exame de escolha para o diagnóstico desta doença, permitindo que seja observada a medida da densidade das opacidades, que, se negativa, caracteriza o acúmulo de lipídios. Em um de nossos casos foram encontradas densidades negativas.

Segundo Franquet et al. ${ }^{(37)}$, a variação na distribuição das opacidades observadas em dois de seus pacientes seria conseqüência das múltiplas aspirações e alterações de postura do corpo, o que é possível transportar para um dos casos deste estudo.

No paciente pediátrico estudado neste trabalho os cortes histológicos demonstraram alvéolos com paredes espessadas por material celular mono e polimorfonuclear, contendo vacúolos de gordura no interior. Áreas de parênquima preservado eram observadas de permeio, separadas por septos interlobulares espessados.

\section{Aspergilose invasiva}

No caso de aspergilose angioinvasiva foram observadas opacidades em vidro fosco circundando irregularmente um nódulo homogêneo (sinal do halo) situado no lobo inferior esquerdo (Figura 10A).

Kuhlman et al. ${ }^{(38)}$ relataram que diagnósticos precoces de aspergilose invasiva puderam ser feitos ao observar o sinal do halo em pacientes com leucemia. Eles correlacionaram este achado tomográfico com a presença de hemorragia ou infartos hemorrágicos circundando as lesões parenquimatosas pulmonares pelo parasito.

O estudo anatomopatológico mostrou alvéolos preenchidos por fibrina e hemorragia, circundando uma área necrótica formada por hifas e envolta por células inflamatórias (Figura 10B), o que está de acordo com a literatura ${ }^{(1,38)}$.

\section{Hemossiderose idiopática}

Foi estudado um paciente com hemossiderose idiopática, com opacidades em vidro fosco comprometendo difusa e simetricamente os pulmões, com predomínio nos lobos inferiores. Brônquios levemente dilatados e espessamento dos septos interlobulares também foram vistos.
Não encontramos, na literatura consultada, relato de achados da hemossiderose na TCAR.

O estudo anatomopatológico mostrou hemorragia alveolar maciça. Havia, também, espessamento do interstício, com macrófagos contendo hemossiderina, semelhante ao descrito na literatura ${ }^{(39)}$.

\section{Metástases hematogênicas}

No caso de metástases hematogênicas, as opacidades em vidro fosco predominaram ao redor dos nódulos, que tinham diferentes dimensões. Estas opacidades eram mais evidentes junto aos nódulos maiores, embora nódulos menores também apresentassem halo em vidro fosco (Figura 11A). Este aspecto (sinal do halo) foi relatado por Hirakata et al. ${ }^{(\mathbf{4 0})}$, como eventualmente encontrado circundando nódulos metastáticos.

O estudo anatomopatológico revelou ocupação alveolar por hemorragia ao redor dos nódulos neoplásicos (Figura 11B).

\section{Aspectos particulares do padrão em vidro fosco}

\section{a) Pavimentação em mosaico}

O padrão em pavimentação em mosaico foi encontrado no presente trabalho em quatro diferentes doenças: carcinoma bronquíolo-alveolar (quatro casos), pneumocistose (três casos), em um caso de pneumonia lipídica e em outro de proteinose alveolar. À semelhança do descrito na 


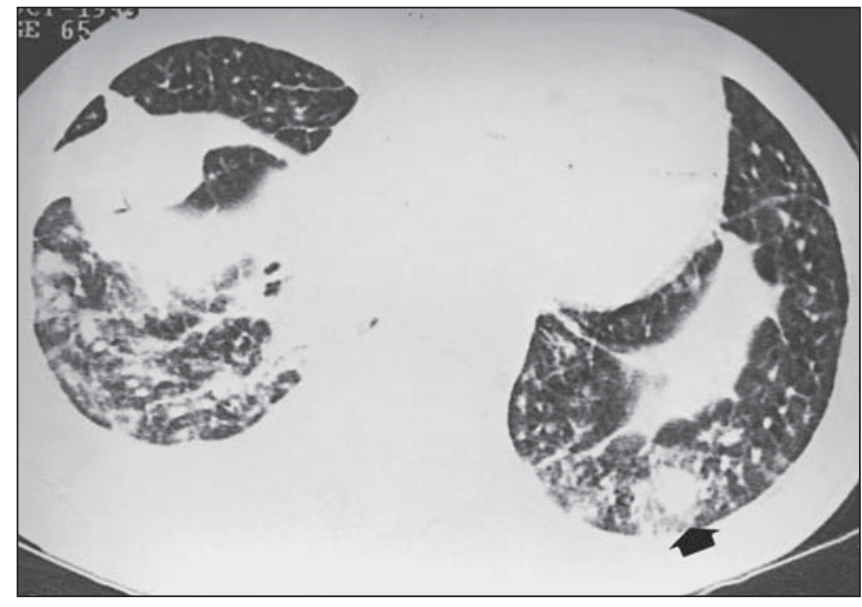

A

Figura 10. Aspergilose angioinvasiva. Em A, TCAR mostrando nódulo circundado por halo irregular com atenuação em vidro fosco no lobo inferior esquerdo (seta), além de áreas esparsas de consolidação e derrame pleural, mais evidentes à direita. Em B (coloração pela prata) evidenciam-se, em negro, as hifas no interior do nódulo, num arranjo radial, e na periferia, espaços alveolares cheios de sangue.

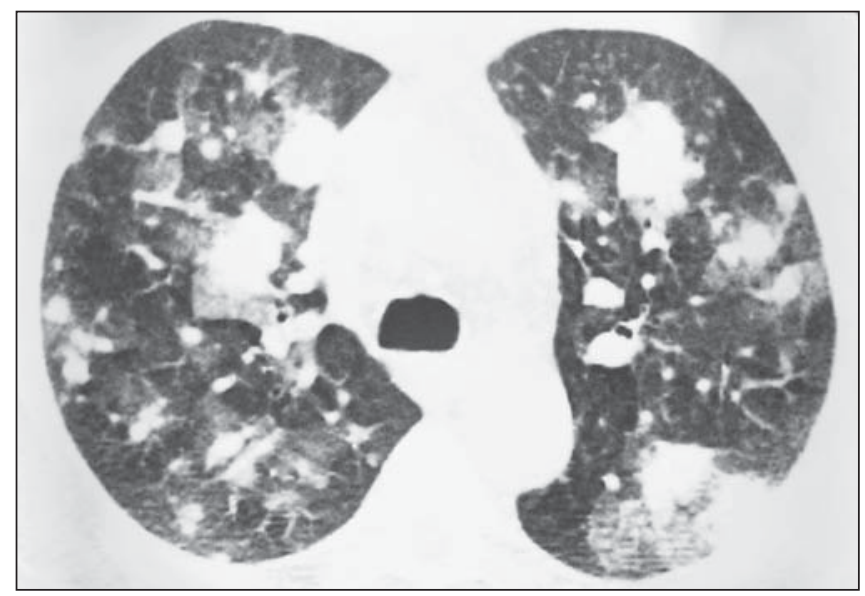

A

Figura 11. Metástases de tumor renal. Em A, TCAR mostrando nódulos distribuídos aleatoriamente nos pulmões, vários deles circundados por halo em vidro fosco. Em B, corte histológico demonstrando a presença de nódulo tumoral e hemorragia ocupando espaços alveolares.

literatura ${ }^{(\mathbf{1 9 , 4 1 - 4 3 )}}$, que desfaz a idéia de ser este padrão patognomônico da proteinose alveolar $^{(\mathbf{4 3})}$, a pavimentação em mosaico tem sido descrita em um número cada vez maior de doenças, demonstrando assim a sua inespecificidade.

\section{b) Sinal do halo}

O sinal do halo foi encontrado em três diferentes doenças, cujo substrato anatomopatológico correspondeu à hemorragia (no caso de metástase de tumor renal e na aspergilose invasiva) e ao acúmulo de material lipídico na pneumonia lipídica.

A presença de hemorragia configurando o sinal de halo foi relatada exaustivamente na literatura ${ }^{(\mathbf{2 8 , 4 4 - 4 6 )}}$, incluindo causas infecciosas e não-infecciosas. Não en-

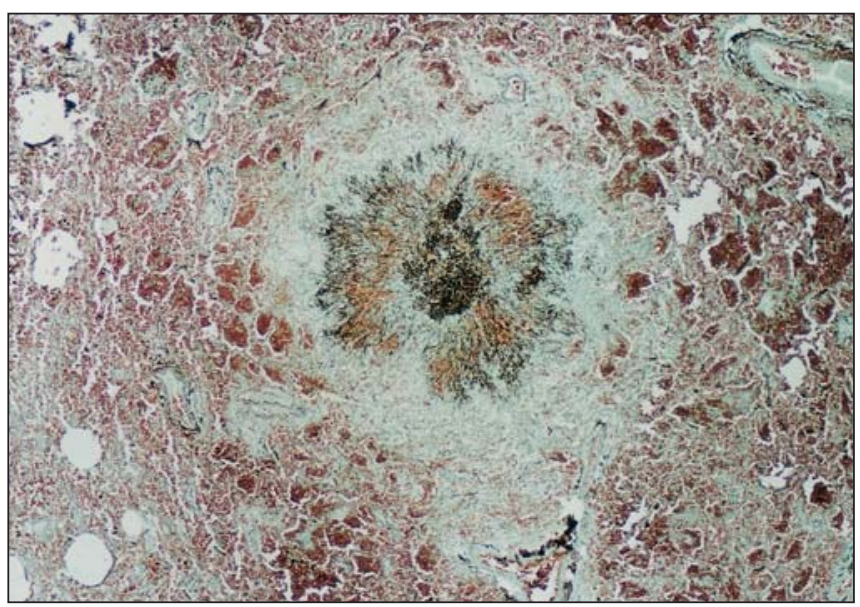

B

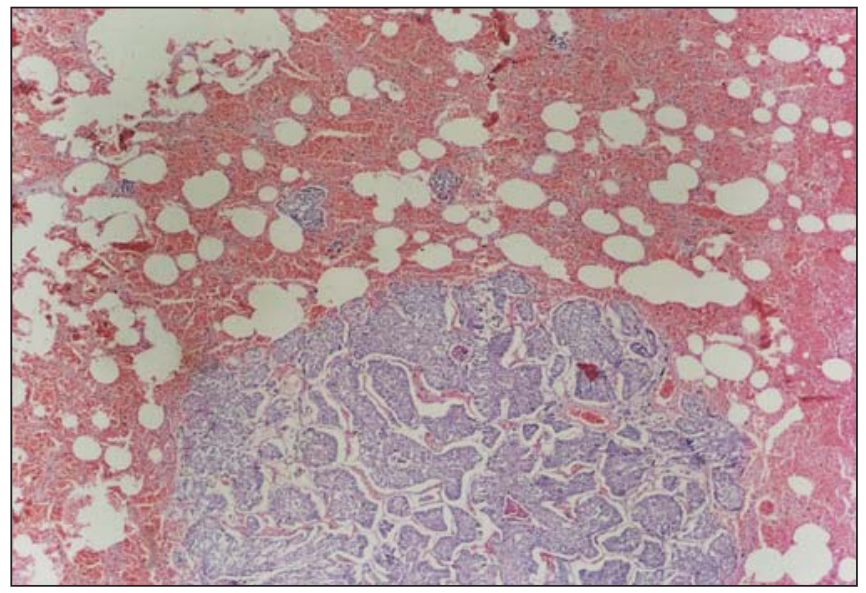

contramos, no entanto, relato do sinal do halo na pneumonia lipídica.

\section{c) Nódulos centrolobulares}

Neste estudo, dois casos de silicoproteinose apresentaram-se como nódulos centrolobulares na TCAR. Este padrão também foi descrito na literatura na pneumonia por hipersensibilidade ${ }^{(47)}$, na pneumonia intersticial descamativa ${ }^{(47)}$ e na proteinose alveolar na infância ${ }^{(48)}$.

\section{Principais substratos} anatomopatológicos causadores do padrão em vidro fosco

Sangue foi o substrato anatomopatológico do padrão em vidro fosco em cinco pacientes, correspondendo a quatro doenças: leptospirose, aspergilose angioinvasiva, hemossiderose e metástases hematogênicas. Nos casos de carcinoma bronquíoloalveolar, o padrão em vidro fosco se deveu tanto ao revestimento dos septos alveolares por células neoplásicas quanto ao acúmulo de muco nos espaços alveolares. Fibrose como causa de padrão em vidro fosco foi observada em três doenças (sarcoidose, paracoccidioidomicose e fibrose pulmonar idiopática), sempre acompanhada de outros sinais, como faveolamento, bronquiectasias ou distorção arquitetural, indicando cronicidade. $\mathrm{Na}$ sarcoidose e na paracoccidioidomicose foi observada, também, infiltração celular inflamatória.

Outros substratos menos comuns para o padrão em vidro fosco foram a presença 
de material lipoprotéico, PAS positivo, observado nos casos de silicose aguda e de proteinose alveolar, vacúolos de gordura na pneumonia lipídica, parasitos e muco na pneumonia por $P$. carinii, edema na insuficiência cardíaca congestiva, e tecido de granulação configurando pólipos intraluminais associados a pneumonia intersticial na bronquiolite obliterante com pneumonia em organização.

Em conclusão, opacidades em vidro fosco são um achado inespecífico, podendo ser encontradas em doenças de diversas etiologias, sendo resultado do comprometimento intersticial, alveolar, ou de ambos, tanto em condições agudas como crônicas, podendo se apresentar isoladamente ou sob a forma de pavimentação em mosaico, sinal do halo, ou nódulos centrolobulares. Quando associadas a alterações intersticiais do parênquima pulmonar, podem ser muito úteis no diagnóstico específico e na avaliação da fase ou do prognóstico da doença.

\section{REFERÊNCIAS}

1. Collins J, Stern EJ. Ground-glass opacity at CT: the ABCs. AJR 1997;169:355-67.

2. Remy-Jardin M, Remy J, Deffontaines C, Duhamel A. Assessment of diffuse infiltrative lung disease: comparison of conventional CT and high-resolution CT. Radiology 1991;181:157-62.

3. Gruden JF, Huang L, Turner J, et al. High-resolution CT in the evaluation of clinically suspected Pneumocystis carinii pneumonia in AIDS patients with normal, equivocal, or nonspecific radiographic findings. AJR 1997;169:967-75.

4. Pereira CIGS, Marchiori E, Souza Jr AS. Pneumocistose no paciente com síndrome da imunodeficiência adquirida: avaliação pela tomografia computadorizada de alta resolução do tórax. Rev Imagem 2001;23:91-9.

5. Primack SL, Müller NL. High resolution computed tomography in acute diffuse lung disease in the immunocompromised patient. Radiol Clin North Am 1994;32:731-44.

6. McGuinness G. Changing trends in the pulmonary manifestations of AIDS. Radiol Clin North Am 1997;35:1029-82.

7. Viegas C, MacGregor RR, Collman EG. Management of Pneumocystis carinii pneumonia in HIVinfected patients: empiric treatment versus microscopic confirmation. J Pneumologia 1997;23:615.

8. Brauner MW, Grenier P, Mompoint D, Lenoir S, Crémoux H. Pulmonary sarcoidosis: evaluation with high-resolution CT. Radiology 1989;172: 467-71.

9. Marchiori E, Melo ASA, Kavakama J, Teixeira GHM, Capone D. Sarcoidose: correlação da tomografia computadorizada de alta resolução com a anatomopatologia. Radiol Bras 2000;33:67-71.

10. Nishimura K, Itoh H, Kitaichi M, Nagai S, Izumi T. Pulmonary sarcoidosis: correlation of CT with histopathologic findings. Radiology 1993;189: 105-9.

11. Funari M, Kavakama J, Shikanai-Yasuda MA, et al. Chronic pulmonary paracoccidioidomycosis (South American blastomycosis): high-resolution CT findings in 41 patients. AJR 1999;173:59-64.

12. Kauer CL. Paracoccidioidomicose: tomografia computadorizada de alta resolução no estudo das alterações pleuropulmonares. (Tese de Doutorado) Porto Alegre: Universidade Federal do Rio Grande do Sul, 2000.

13. Marchiori E, Moraes HP, Muniz MAS, Santos MLO, Capone D. Paracoccidioidomicose: correlação da tomografia computadorizada de alta resolução com a anatomopatologia. Radiol Bras 2000; 33:333-40.

14. Muniz MAS, Marchiori E, Magnago M, Moreira LBM, Almeida Junior JG. Paracoccidioidomicose pulmonar: aspectos na tomografia computadorizada de alta resolução. Radiol Bras 2002;35:147-54.

15. Angulo-Ortega A, Pollak L. Paracoccidiodomycosis. In: Baker RD, ed. The pathologic anatomy of mycosis. Berlin: Springer-Verlag, 1971.

16. Moreira LBM, Marchiori E, Melo ASA, Magnago M, Muniz MAS, Irion K. Carcinoma bronquíoloalveolar: aspectos na tomografia computadorizada de alta resolução. Radiol Bras 2002;35:7-14.

17. Akira M, Atagi S, Kawahara M, Iuchi K, Johkoh T. High-resolution CT findings of diffuse bronchioloalveolar carcinoma in 38 patients. AJR 1999;173: $1623-9$.

18. Jang HJ, Lee KS, Kwon OJ, Rhee CH, Shim YM, Han J. Bronchioloalveolar carcinoma: focal area of ground-glass attenuation at thin-section $\mathrm{CT}$ as an early sign. Radiology 1996;199:485-8.

19. Tan RT, Kuzo RS. High-resolution CT findings of mucinous bronchioloalveolar carcinoma: a case of pseudopulmonary alveolar proteinosis. AJR 1997; 168:99-100

20. Marchiori E, Kavakama J, Capelozzi VL, Vabo KA, Damato SD. "Pavimentação em mosaico": correlação da tomografia computadorizada de alta resolução com a anatomopatologia. Radiol Bras 2000; 33:169-73

21. Marchiori E, Moreira LBM, Melo ASA, Capone D, Moraes HP. Carcinoma bronquíolo-alveolar: correlação da tomografia computadorizada de alta resolução com a anatomopatologia. Rev Imagem 2000;22:123-9.

22. Kobayashi T, Satoh K, Sasaki M, et al. Bronchioloalveolar carcinoma with widespread ground-glass shadow on CT in two cases. J Comput Assist Tomogr 1997;21:133-5.

23. Katzenstein ALA, Fiorelli RF. Nonspecific interstitial pneumonia/fibrosis. Histologic features and clinical significance. Am J Surg Pathol 1994;18: 136-47.

24. Akira M, Yamamoto S, Sakatani M. Bronchiolitis obliterans organizing pneumonia manifesting as multiple large nodules or masses. AJR 1998;170 291-5.

25. Lee KS, Kullnig P, Hartman TE, Müller NL. Cryptogenic organizing pneumonia: $\mathrm{CT}$ findings in 43 patients. AJR 1994;162:543-6.

26. Machado DM, Marchiori E, Malheiros NR, et al. Bronquiolite obliterante com pneumonia em organização (BOOP) - relato de um caso. Radiol Bras 1994;27:239-43.

27. Nishimura K, Itoh H. High-resolution computed tomographic features of bronchiolitis obliterans organizing pneumonia. Chest 1992;102(1 Suppl.): 26S-31S.

28. Preidler KW, Szolar DM, Moelleken S, Tripp R,
Schreyer H. Distribution pattern of computed tomography findings in patients with bronchiolitis obliterans organizing pneumonia. Invest Radiol 1996;31:251-5.

29. Storto ML, Kee ST, Golden JA, Webb WR. Hydrostatic pulmonary edema: high-resolution CT findings. AJR 1995;165:817-20.

30. Marchiori E, Müller NL. Leptospirosis of the lung: high-resolution computed tomography findings in five patients. J Thorac Imaging 2002;17:151-3.

31. Carvalho JEM, Marchiori ES, Silva JBG, Souza Netto BA, Tavares W, Paula AV. Comprometimento pulmonar na leptospirose. Rev Soc Bras Med Trop 1992;25:21-30.

32. Coulier B, Mailleux P, Mairesse M, Bachez P. Alveolar proteinosis; signs and prognosis using highresolution computed tomography in 5 patients. JBR-BTR 1999;82:277-81.

33. Crocker HL, Pfitzner J, Doyle IR, Hague WM, Smith BJ, Ruffin RE. Pulmonary alveolar proteinosis: two contrasting cases. Eur Respir J 2000;15: 426-9.

34. Graham WGB. Silicosis. Clin Chest Med 1992;13: 253-67.

35. Marchiori E, Ferreira A, Müller NL. Silicoproteinosis: high-resolution $\mathrm{CT}$ and histologic findings. J Thorac Imaging 2001;16:127-9.

36. Wheeler PS, Stitik FP, Hutchins GM, Klinefelter HF, Siegelman SS. Diagnosis of lipoid pneumonia by computed tomography. JAMA 1981;245:65-6.

37. Franquet T, Giménez A, Bordes R, Rodriguez-Arias JM, Castella J. The crazy-paving pattern in exogenous lipoid pneumonia: CT-pathologic correlation. AJR 1998;170:315-7.

38. Kuhlman JE, Fishman EK, Siegelman SS. Invasive pulmonary aspergillosis in acute leukemia: characteristic findings on CT, the CT halo sign, and the role of CT in early diagnosis. Radiology 1985;157:6114.

39. Theros EG, Reeder MM, Eckert JF. An exercise in radiologic-pathologic correlation. Radiology 1968; 90:784-91.

40. Hirakata K, Nakata H, Nakagawa T. CT of pulmonary metastases with pathological correlation. Semin Ultrasound CT MR 1995;16:379-94.

41. Hartman TE, Primack SL, Müller NL, Staples CA. Diagnosis of thoracic complications in AIDS: accuracy of CT. AJR 1994;162:547-53.

42. Murayama S, Murakami J, Yabuuchi H, Soeda H, Masuda K. "Crazy-paving appearance" on high resolution CT in various diseases. J Comput Assist Tomogr 1999;23:749-52.

43. Murch CR, Carr DH. Computed tomography appearances of pulmonary alveolar proteinosis. Clin Radiol 1989;40:240-3.

44. Brown MJ, Miller RR, Müller NL. Acute lung disease in the immunocompromised host: $\mathrm{CT}$ and pathologic examination findings. Radiology 1994; 190:247-54

45. Curtis AMB, Smith GJW, Ravin CE. Air crescent sign of invasive pulmonary aspergillosis. Radiology 1979;133:17-21.

46. Primack SL, Hartman TE, Lee KS, Müller NL. Pulmonary nodules and the CT halo sign. Radiology 1994;190:513-5.

47. Engeler CE, Tashjian JH, Trenkner SW, Walsh JW. Ground-glass opacity of the lung parenchyma: a guide to analysis with high-resolution CT. AJR 1993;160:249-51.

48. Albafouille V, Sayegh N, De Coudenhouve S, et al. CT scan patterns of pulmonary alveolar proteinosis in children. Pediatr Radiol 1999;29:147-52. 